has since appeared in the Bagdad paper el Bilad evades this issue. Dr. Woolley goes on to show specifically in detail that the Antiquities Department of Iraq, having first choice, was in a position to, and did, select the most valuable and finest specimens for its proportion of the finds, without any compensation being given to the Expedition. The law is interpreted in such a way that there is a danger that the share of any Expedition may become insufficient to justify the expenditure entailed by the work of excavation. The reduction of the number of expeditions in this field to three indicates that this view is only too well founded.

\section{Artificial Lighting at the National Gallery}

ON and after April 1 the public will be able to visit the National Gallery, Trafalgar Square, until 8 p.m. on three evenings in the week. This has been made possible by a new lighting scheme, which has been the subject of extensive research during the past six years. The installation has been designed to secure a reasonably high intensity-about 4 footcandles-upon the pictures themselves, and at the same time to prevent too great a feeling of darkness over the remainder of the room. Suspended fittings, each containing a high-powered frosted bulb, are used, and a system of louvers and reflectors directs as much light towards the picture-carrying portion of the walls as the architecture of the several rooms will permit. The height of the fittings has been calculated upon the assumption of a viewing distance of eleven feet from the walls. Masks are employed to stop the glare in the direction of doorways : in the majority of cases this has proved satisfactory, though instances will always arise when the geometry cannot be satisfied without producing a shadow on the wall or in a corner. An emergency system of lighting, which comes into operation automatically in case of failure, is held in reserve.

\section{International Vitamin Standards}

THE International Standards for vitamins A, B , C and $\mathrm{D}$ are now available for issue to laboratories, institutions and research workers in Great Britain and Northern Ireland. These standards were accepted for international use at the Second International Conference on Vitamin Standardisation held in London in June 1934 under the auspices of the Permanent Commission on Biological Standardisation of the Health Organisation of the League of Nations. The Conference recommended that they should be kept at the National Institute for Medical Research, Hampstead, N.W.3, which would act for this purpose as the central laboratory on behalf of the Health Organisation of the League of Nations. The standards for the vitamins $B_{1}$ and $D$ remain unchanged, and their supply at regular half-yearly intervals will be continued as before. The standard for vitamin A has been changed; a pure specimen of $\beta$-carotene having been adopted in place of the impure preparation of carotene hitherto employed. The unit of vitamin A remains unchanged, though it is now defined as the vitamin $A$ activity contained in 0.6 microgram of pure $\beta$-carotene. In accordance with the recommendations of the Conference, the $\beta$. carotene is issued in the form of a solution in oil, of which $1 \mathrm{gm}$. contains 500 international units. 'The quantity of this standard solution supplied to each applicant is approximately $5 \mathrm{gm}$, and, on account of the small quantity available, it can be supplied only at yearly intervals, and not half-yearly as formerly. $l$-Ascorbic acid has been adopted as the international standard for vitamin $\mathrm{C}$, the unit of activity being defined as the vitamin $\mathrm{C}$ activity contained in 0.05 mgm. of pure $l$-ascorbic acid. A fuller account of the recommendations of the Conference on Vitamin Standardisation appears elsewhere in this issue (p. 516).

\section{Chemical Engineering in Industry}

Great Britain is awakening to the importance of the chemical engineer, a man who knows the nature and properties of the new constructional materials or is able to design large plants for the continuous production of those materials which are classed as chemicals. It is at least likely that the big developments in the future will be among the chemical industries making, at a low price, substances for which there is a considerable need, almost auto. matically as a continuous process. Such will require the ablest chemical engineers to design and operate them. There are two societies active in promoting the subject and in bringing together those who practise it, and post-graduate courses are provided in several of the London colleges. Greater progress in chemical engineering has been made abroad, particularly in the United States and in Germany, and for some time past the desirability of holding an international congress has been realised by those interested, in particular by the late Sir Frederic Nathan. Thanks to the assistance of the World Power Conference with its widespread organisation, a Congress has now been arranged, to take place in London on June 22-27, 1936. The programme, which has just been issued, lists the influential members of the organising committees, whose names are a guarantee of the support the Congress is receiving. It further indicates the scope of the projected programme : this covers plant, fuel and heat and general problems, administration, development and general aspects of the subject. It is desired that the papers, while adhering strictly to chemical engineering, should deal as fully as possible with the economic aspect of the subject. The Committee aims at inviting technicians of repute to present papers dealing with particular aspects of these subjects rather than having a miscellaneous collection of papers, and if they are successful the Congress should be a memorable one.

\section{Dr. William Derham, F.R.S. (I657-1735)}

ON April 5, the bicentenary occurs of the death of Dr. William Derham, rector of Upminster, Essex, and for thirty-three years a fellow of the Royal Society. Born at Stoughton, near Worcester, on November 26, 1657, he entered Trinity College, 